\title{
Between a cough and a wheeze: dendritic cells at the nexus of tobacco smoke-induced allergic airway sensitization
}

\author{
LJ Robays $^{1,2}$, T Maes ${ }^{1}$, GF Joos ${ }^{1}$ and KY Vermaelen ${ }^{1}$
}

Exposure to cigarette smoke represents a major risk factor for the development of asthma. Enhanced sensitization toward allergens has been observed in humans and laboratory animals exposed to cigarette smoke. Pulmonary dendritic cells (DCs) are crucially involved in sensitization toward allergens and play an important role in the development of T helper (Th)2-mediated allergic airway inflammation. We propose the concept that aberrant DC activation forms the basis for the deviation of the lung's default tolerogenic response toward allergic inflammation when harmless antigens are concomittantly inhaled with tobacco smoke. This review will summarize evidence suggesting that tobacco smoke can achieve this effect by providing numerous triggers of innate immunity, which can profoundly modulate airway DC biology. Tobacco smoke can affect the airway DC network either directly or indirectly by causing the release of DC-targeted mediators from the pulmonary tissue environment, resulting in the induction of a Th2-oriented pathological immune response. A thorough knowledge of the molecular pathways involved may open the door to novel approaches in the treatment of asthma.

\section{SMOKING AND ASTHMA: FROM EPIDEMIOLOGICAL DATA TO MOUSE MODELS}

Asthma is a chronic airway disease characterized by recurrent attacks of breathlessness and wheezing, which may vary in severity and frequency (www. ginasthma.org). The bronchial hyper-reactivity underlying these symptoms originates from an improper pulmonary inflammatory response toward common aeroallergens or air pollutants. This aberrant immune response is characterized by airway eosinophilia, goblet cell hyperplasia, airway wall remodeling, and production of allergen-specific IgE, all driven by $\mathrm{T}$ helper (Th)2-derived cytokines, such as interleukin (IL)-4, IL-5, and IL-13. ${ }^{1}$ Asthma rates have surged the last decades, and this has invigorated interest in the genetic and environmental risk factors contributing to this major public health problem. Epidemiological data have associated cigarette smoke exposure with the development and the severity of asthmatic disease. ${ }^{2,3}$ In selected individuals, active smoking can thoroughly worsen the symptoms of asthma, precipitate a more pronounced decline in lung function over the years, and impair therapeutic responses to corticosteroids. ${ }^{4,5}$
Several studies have implicated environmental tobacco smoke exposure in utero or during infancy in the development of childhood asthma (reviewed in ref. ${ }^{6}$ ). Exposure to maternal smoking in utero exacerbates Th2-oriented responses in neonates and increases the risk of sensitization to house dust mite in later life. ${ }^{7,8}$ One study revealed that circulating dendritic cells (DCs) from infants exposed to environmental tobacco smoke produced less of the immunosuppressive cytokine IL-10 in vitro. ${ }^{9}$ There are fewer reports on the role of active cigarette smoking in the triggering of asthma in later life. One large prospective cohort study showed an increased risk for new-onset asthma in smoking adolescents, which surprisingly enough was more pronounced in subjects without allergic predisposition. ${ }^{10}$ Smoking also appears to be associated with an increased risk of developing asthma in adulthood, both in the presence and in the absence of atopic background. ${ }^{11}$

In light of these epidemiological data, laboratory animal models have been developed to gain a better understanding of the complex interaction between smoking and allergic airway inflammation. In these models, active smoking in human

${ }^{1}$ Department of Respiratory Medicine, Ghent University Hospital, Ghent, Belgium. ${ }^{2}$ Laboratory of Molecular and Cellular Therapy, Department of Physiology and Immunology, Medical School of the Vrije Universiteit Brussel, Brussel, Belgium. Correspondence: K Vermaelen (karim.vermaelen@ugent.be) 
subjects is reproduced by exposing animals to cigarette smoke collected at the filter end of the cigarette ("mainstream" smoke), whereas passive smoking is mimicked by exposing animals to environmental smoke from the lit end of a smoldering cigarette ("sidestream" component). The concentration of smoke to which animals are exposed varies widely among different laboratories, depending on the use of collective "whole-body" exposure chambers, vs. individual exposure devices (whole body or "nose-only"). These methodological variations likely explain the diverging observations among different research groups. Several laboratories have reported that both environmental and mainstream cigarette smoke exposure of allergen-sensitized mice profoundly aggravated the allergic inflammatory response in the lung and increase airway hyper-reactivity. ${ }^{12,13}$

In contrast, other groups describe attenuation of previously established allergic inflammation after mainstream cigarette smoke exposure. ${ }^{14,15} \mathrm{~A}$ recent study by Thatcher et al. ${ }^{16}$, by addressing the dose-dependent properties of mainstream tobacco smoke exposure on allergic response, highlighted the exposure regimen as a critical parameter in the outcome of cigarette smoking on the asthmatic phenotype in these models.

More intriguing than the impact of smoking on the severity of pre-established asthma, tobacco smoke appears to possess adjuvant properties in the initial recognition of allergens by the immune system, resulting in the induction of Th2 responses. Concomitant inhalation of mainstream cigarette smoke with aerosolized harmless antigen - without prior sensitization-elicited features of allergic inflammation in mice, characterized by peribronchial eosinophilic infiltrates, goblet cell hyperplasia, enhanced levels of allergen-specific serum IgE, and IL-5 production in draining lymph nodes (LNs). ${ }^{17,18}$ The establishment of allergen-specific T-cell memory is a variable finding among different reports in this model. ${ }^{17-19}$ By contrast, experiments from our group and others consistently revealed an expansion of airway DC numbers, which was greater in the combined exposure regimen compared with allergen or smoke inhalation alone. ${ }^{13,17,18}$ Interestingly, the combined exposure triggered an enhanced production of the Th2-attracting chemokine, CCL17. The main source of CCL17 in the lung was shown to originate from pulmonary DCs themselves. ${ }^{20}$

However, not all studies found a positive contribution of cigarette smoke to the sensitization phenomenon. When protein antigen was not inhaled as an aerosolized solution, but rather administered through the intranasal route, environmental tobacco smoke exposure failed to trigger the antigen-specific immune response to inhaled antigens. ${ }^{21}$ Again, this illustrates the importance of the experimental setup used for the outcome of cigarette smoke-induced allergic sensitization. In our hands, a combined challenge protocol (i.e., smoke exposure and aerosolized antigens given simultaneously) was able to break the default tolerogenic response in the lung and favor the development of a pro-allergic response. ${ }^{17}$ Furthermore, in a model of inhalational tolerance, prolonged cigarette smoke exposure of mice significantly delayed the establishment of tolerance induced by repeated harmless antigen challenges. ${ }^{22}$

In this review, we will provide insights into the molecular and cellular events underlying the phenomenon of tobacco smoke-induced allergen sensitization. Given the central role of DCs in the immunological homeostasis of the airway mucosa, we will highlight the effects of tobacco smoke on pulmonary DC biology, and propose mechanisms through which tobacco smoke-exposed airway DCs could trigger allergic responses.
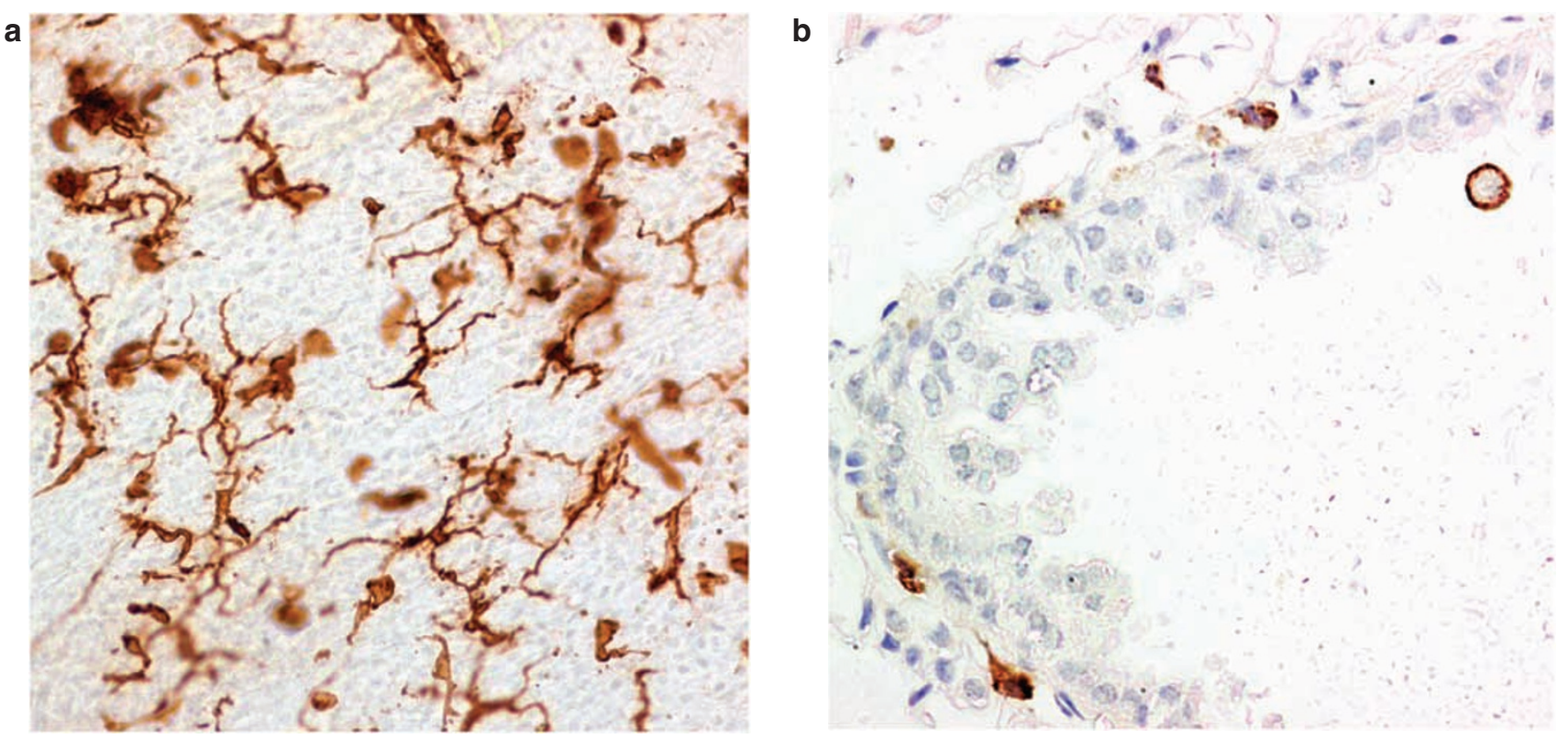

Figure 1 Distribution and localization of airway DCs. (a) Distribution and morphology of the pulmonary DC network in the large conducting airways as revealed by MHCIl staining on tracheal whole mount sections of a naive mouse. (b) Subepithelial localization of CD11c-positive DCs (brown) on a crosssectional view of murine airway tissue. The CD11c+ cell with a round morphology in the airway lumen represents a macrophage. DC, dendritic cell. 


\section{AIRWAY DCS: IMMUNOLOGICAL SENSORS OF ENVIRONMENTAL AIR QUALITY}

The lung is constantly exposed to airborne antigens, hence a thorough surveillance of this large organ by the immune system is of vital importance. For this purpose, a dense network of airway DCs is distributed along the entire tracheobronchial tree as well as in the interalveolar septae and constantly surveys the content of inhaled air ${ }^{23,24}$ (Figure 1a). Originally derived from the bone marrow, DCs travel as precursors through the blood circulation, migrate to peripheral tissues, such as the lung, and position themselves as immature cells just beneath the epithelial layers (Figure 1b). From there, they are ideally situated to extend their tentacle-like cytoplasmic processes into the airway lumen in which contact may occur with inhaled material caught in the mucociliary layer. ${ }^{25,26}$ Equipped with specialized receptors for antigen uptake, the pulmonary DC network represents a highly differentiated and sophisticated antigen recognition system. The strength of this system lies in the ability to discriminate harmless from harmful inhaled substances. Invading microorganisms can be sensed through specific pathogen-associated molecular patterns recognized by pathogen recognition receptors on DCs, such as Toll-like receptors (TLRs), C-type lectin receptors, cytosolic Nod-like receptors, and rig-like receptors. ${ }^{27,28}$ In addition to these exogenous danger signals, DCs integrate signals from stressed or damaged host cells (damage-associated molecular patterns), allowing them to detect a breach in tissue and cellular integrity. ${ }^{29}$ The convergence of these danger signals informs the DC about inhaled material that poses an immediate threat to pulmonary tissues and activates a maturation program: DCs process sampled antigen, present it on major histocompatibility (MHC) molecules, and strongly increase T-cell costimulatory molecule expression on their surface. At the same time, activated DCs acquire the capacity to home for lymphatic vessels and leave the antigen-exposed epithelium toward draining LNs. These migratory DCs specifically penetrate the T-cell-rich paracortical zones and transmit a package of information consisting of processed antigen, along with costimulatory signals and secreted factors, that will program the ensuing T-cell response: tolerogenic, Th1, Th2, or Th17. A large body of experimental data validates the concept that the emerging $\mathrm{T}$-cell polarization is determined by the molecular conditioning of the DCs at the site and moment of antigen encounter in the periphery.

\section{AIRWAY DCS ARE MASTER REGULATORS OF ALLERGIC RESPONSES}

A decado ago, DCs were identified upstream in the inflammatory cascade leading to a Th2-driven inflammation in the lung. ${ }^{30,31}$ Instillation of bone-marrow-derived, allergen-loaded DCs into the airways was sufficient to sensitize mice to a model allergen and induce a strong eosinophilic airway inflammation upon allergen rechallenge. ${ }^{32}$ Moreover, it was shown that allergic sensitization to inhaled inocuous antigen could be repressed by a trace population of so-called plasmacytoid DCs residing in the lung periphery. ${ }^{33}$

In addition to their involvement in the sensitization process, DCs play a non-redundant role in the local maintenance of allergic responses and the severity of disease. Important evidence for this concept came from depletion studies in which DCs were selectively eliminated during ongoing allergic inflammation in the lung. ${ }^{34}$ The complete abrogation of asthma-like symptoms in DC-depleted airways of mice challenged the view that primed Th2 cells required no additional reactivation by antigen-presenting cells for their effector function. Instead, airway DCs were found to actively contribute to the maintenance of allergic disease by recruiting and activating recirculating Th2 memory cells. In addition, bidirectional interactions of DCs with allergen-specific $\mathrm{T}$ cells lead to reciprocal activation and preceded the late-phase asthmatic response. ${ }^{35}$ Furthermore, ongoing allergic inflammation alters important features of pulmonary DC biology in a way that further consolidates the perpetuation of these inappropriate Th2 responses. First, DCs are recruited in massive amounts to the airways during allergic inflammation, which is supported by a proliferation of early DC precursors in the bone marrow. ${ }^{36-38}$ Second, DCs in inflamed airways are unusually activated compared with DCs in healthy lungs. ${ }^{36}$ Cell surface expression of MHCII and T-cell costimulatory molecules is markedly enhanced, whereas levels of inducible costimulator-ligand (ICOS-L), an inhibitory molecule involved in IL-10dependent inhalational tolerance, ${ }^{39}$ are decreased. With respect to the recently described two major pulmonary DC subsets, it appears that allergic airway inflammation primarily expands the CD11b-high/CD103-negative DC subpopulation, which is a powerful producer of inflammatory chemokines. ${ }^{40,41}$ However, the CD11b-negative/CD103-high DC subset, which specifically resides within the airway epithelium, secretes the highest amount of the Th2-attracting chemokine, CCL22, on a per cell basis. Third, airway inflammation strongly invigorated antigen transport and emigration of airway DCs from allergen-challenged lungs to draining LNs. ${ }^{36}$ Changes in airway DC numbers were also observed in human subjects with asthmatic disease, suggesting a role for the airway DC network in human asthma as well. In asthmatic patients, allergen challenge caused a drop in circulating blood myeloid DC numbers, ${ }^{42}$ whereas a rapid accumulation of myeloid DCs occurred in the bronchial mucosa. ${ }^{43}$ Furthermore, increased numbers of DCs in bronchial biopsies of asthmatic subjects are suppressed by inhaled corticosteroids. ${ }^{44}$

\section{TOBACCO SMOKE AFFECTS ALL THE ASPECTS OF AIRWAY DC BIOLOGY}

To understand how tobacco smoke exposure can disturb the immunological balance in the lung and promote allergic sensitization, it is important to outline the effects of tobacco smoke by itself on pulmonary DCs. From a physiological point of view, tobacco smoke exposure corresponds to excessive amounts of hot, noxious gases, toxic particles, and chemicals sweeping across the airways. The superficial airway DC network is at the forefront of this harmful influence, and not surprisingly smoke has profound impact on several aspects of DC biology, such as population turnover and activation (Figure 2).

\section{Tobacco smoke affects pulmonary DC recruitment}

Cigarette smoke-induced pulmonary inflammation is characterized by the infiltration of lower airways with neutrophils, 


\section{Effects of tobacco smoke on DC biology}
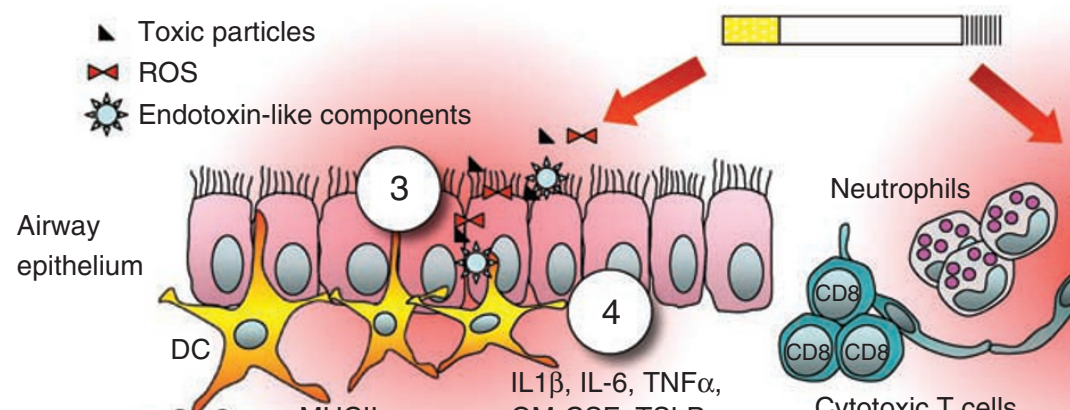

IL1 $\beta$, IL-6, TNF $\alpha$,

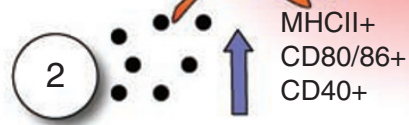

GM-CSF, TSLP

Cytotoxic T cells

ROS, danger signals

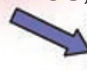

CCL2, CCL20,

chemerin, elastin, defensins, cathelicidin, $2 \mathrm{CCR} 2+$ lactoferrin, cathepsin GO CCR6+
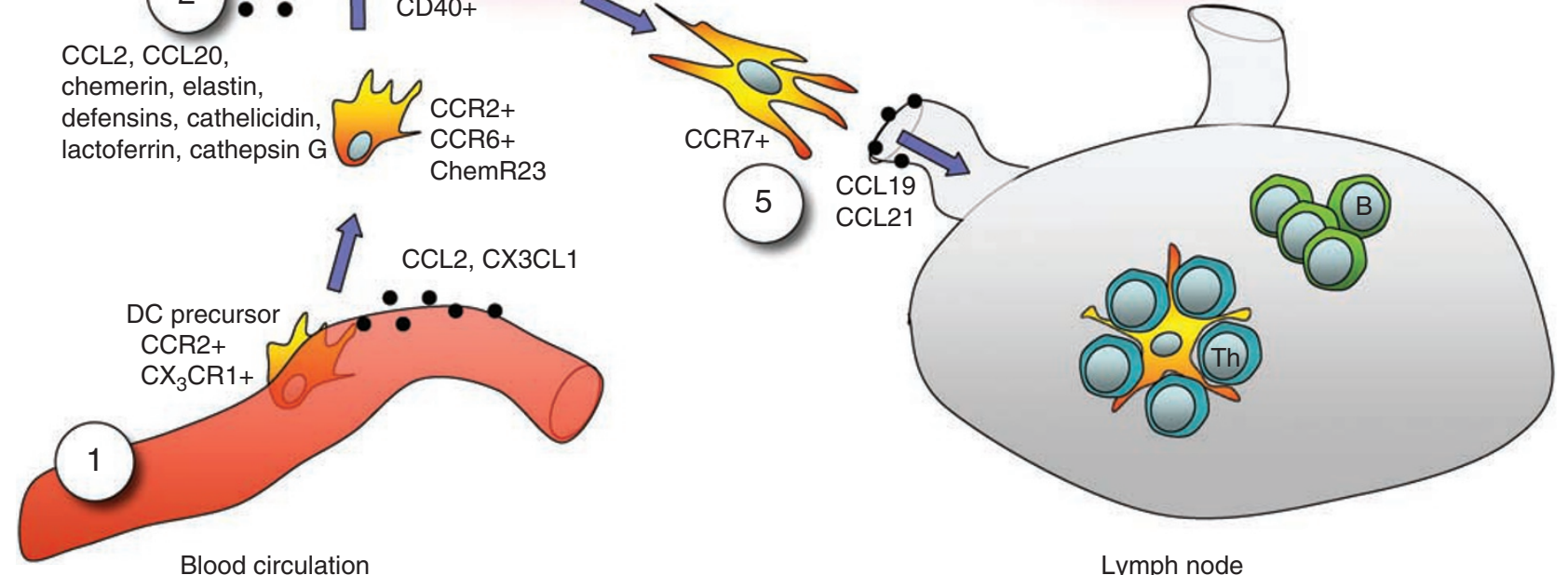

Lymph node

Figure 2 Effects of tobacco smoke on different aspects of pulmonary DC biology. Tobacco smoking induces a pronounced pulmonary inflammation characterized by an influx of macrophages, neutrophils, CD8 + T cells, and DCs into the lumen and lung tissues. (1) Exposure to cigarette smoke results in an increase in several potential DC-attracting mediators acting on DC precursors in the circulation or immature DCs in lung tissue. DC precursors in the blood express chemokine receptors, CCR2 and $\mathrm{CX}_{3} \mathrm{CR} 1$, which renders them responsive to CCL2 and CX ${ }_{3} \mathrm{CL} 1$ presented on the lung vascular tissue. (2) In pulmonary tissue, DCs are further recruited toward epithelial tissues by CCL20 and defensins, interacting with CCR6, or chemerin, interacting with ChemR23 on immature DCs. Neutrophil-derived products, such as cathelicidin, lactoferrin, and cathepsin G, and matrixdegradation products, such as elastin, also have monocyte- and DC-attractive potential. (3) Once located in epithelial regions, DCs sample the mucosa for inhaled antigens while acting as immunological sensor for the presence of hazardous triggers. Tobacco smoke exposure has the potential to activate the airway DC network through several mechanisms. DC activation can occur through direct contact with cigarette smoke-derived compounds, such as endotoxins, toxic particles, and oxidizing agents. (4) Alternatively, DCs respond to inflammatory mediators released in the local pulmonary environment as a result of the biological damage inflicted by tobacco smoke. These mediators include several pro-inflammatory cytokines, such as TNF- $\alpha$, IL-6, GM-CSF, and TSLP, reactive oxygen species (ROS) and danger signal-like heat-shock proteins (Hsps), high-mobility group box-1 (HMGB1), and uric acid. DC activation results in the upregulation of MHCIl and costimulatory molecules, such as CD80, CD86, and CD40. (5) DC maturation additionally induces the expression of CCR7, the chemokine receptor that interacts with CCL21 expressed on draining lung lymphatics and triggers DC emigration toward draining LNs. In T-cell areas of thoracic LNs, DCs interact with antigen-specific naive T cells and induce adaptive immune responses depending on the innate immune stimuli received from cigarette-exposed peripheral lung tissue. DC, dendritic cell; GM-CSF, granulocyte macrophage colony-stimulating factor; LN, lymph node; TNF- $\alpha$, tumor necrosis factor- $\alpha$.

monocytes/macrophages, and cytotoxic CD8 T cells. Increased numbers of DCs are found very early in the airway compartment of cigarette smoke-exposed murine lungs. ${ }^{45,46} \mathrm{~A}$ detailed analysis of the inflammatory infiltrates in a mouse model of chronic obstructive pulmonary disease (COPD) revealed that DC numbers in the airways raised gradually after a short period of continual smoking, reaching 10 -fold levels after a chronic exposure for 6 months compared with the numbers in shamexposed animals. ${ }^{45}$ Lung tissue sections were also found to contain temporarily increased numbers of Langerhans cell-like DCs after passive exposure of mice to tobacco smoke. ${ }^{47}$ Chronic exposure of mice leads to a pronounced peribronchial infiltration of the small airway bronchial lesions with MHCII + B220 cells. ${ }^{45}$ However, another group found decreased DC numbers in the peripheral lung after tobacco smoke exposure of mice. ${ }^{48,49}$ Probably, the effects on DC numbers are confined to the regions in close contact to the inhaled tobacco smoke, such as airway lumen, mucosa, and peribronchial tissue, and less detectable on whole lung tissue specimens. In humans, the accumulation of DCs was observed in bronchial biopsy specimens and bronchoalveolar fluid of smokers. ${ }^{50-53}$ On the other hand, smokers with asthma had less CD83 + (i.e., mature) DCs in endobronchial 
biopsies of the large airways. ${ }^{54}$ The increase in DC numbers after cigarette smoking in humans has led to the hypothesis that these cells play a role in the pathogenesis of COPD (discussed in detail in ref. ${ }^{55}$ ).

Protein levels of the inflammatory CC-chemokine CCL20 were significantly elevated in the bronchoalveolar lavage (BAL) fluid of cigarette smoke-exposed mice. ${ }^{56}$ This correlated with the increased numbers of DCs expressing the chemokine receptor CCR6, suggesting a contribution of this chemokine in the recruitment of DCs to the lungs. Furthermore, the increase in BAL DCs was attenuated in CCR6 - / - mice after cigarette smoke exposure in both the subacute (1 month) and the chronic (6 month) COPD mouse model. ${ }^{56}$ In humans, increased numbers of DCs were associated with the enhanced production of CCL20 and correlated with disease progress in COPD patients. ${ }^{57}$ Alveolar type-II cells represent a rich source of chemokines and produce high levels of CCL20 in inflammatory conditions. ${ }^{58}$ Conditioned media from these type II pneumocytes specifically attracted blood monocyte-derived CD1a + DCs through CCL20. This points to the important role of lung structural cells in pulmonary DC trafficking and that CCL20 might be involved in this process. However, the inducible autocrine production of CCL20 by human monocytes and monocyte-derived DCs themselves, in addition to other innate cells such as neutrophils and macrophages, warrants for a more complex regulation of the chemokine network in the lung. ${ }^{59}$ Alternatively, CCR2 receptor might be primarily involved in the migration of DC (and their precursors) to the lung, concordant with the findings in allergic mice. ${ }^{60}$ Enhanced levels of CCL2 (also known as monocyte chemotactic protein-1, and an important CCR2 ligand) were observed in the lung of cigarette smoke-exposed mice and in patients with COPD. ${ }^{46,56,61}$ In addition, cigarette smoke extract induced monocyte chemotactic activity by lung epithelial cells and fibroblasts in vitro through the release of CCL2. ${ }^{62,63}$ The early production of CCL2 after an acute cigarette smoke exposure in mice correlated with the influx of monocytes/macrophages (and, based on the morphological criteria, presumably also DCs) in lung tissue and lumen, similar to what has been observed in allergic lungs. ${ }^{64}$ However, it could be that DC recruitment during allergic inflammation vs. smoke-induced inflammation is governed by distinct chemokine-receptor networks. Furthermore, other chemotactic molecules released upon cigarette smoke exposure could additionally attract DCs or their precursors to the lung. Release of the activated complement cleavage product $\mathrm{C} 5 \mathrm{a}$ was linked to the recruitment and differentiation of monocytes into DCs. ${ }^{65}$ Several pathways of the complement system are indeed activated in response to cigarette smoke or smoke extract in vitro. ${ }^{66}$ Also, elastin fragments, generated as a result of proteolysis of elastin fibers by neutrophil elastase or the protease MMP-12 during chronic smoke exposure, were shown to promote the recruitment of monocytes. ${ }^{67}$ Neutrophil infiltration is a cardinal feature of smoke-induced airway inflammation in humans and mice. Several neutrophil degranulation products with antimicrobial properties, such as defensins, cathelicidin, lactoferrin, and cathepsin G, are chemotactic for monocytes and DCs. ${ }^{68-70}$ Interestingly, degranulated neutrophils release the proteases elastin and cathepsin G, which cleave prochemerin into its biologically active form, chemerin, that can specifically attract DCs through its receptor ChemR23. ${ }^{71,72}$

\section{Tobacco smoke affects DC activation}

Next to the effects on pulmonary DC migration and trafficking, tobacco smoking appears to have profound effects on the activation status of pulmonary DCs. As already pointed out, the level of DC activation is a key determinant of the immunogenicity of this cell. DCs in the airway compartment express enhanced levels of MHCII and the maturation markers, CD80, CD86, and CD40, in smoke-exposed mice and humans compared with non-smokers. ${ }^{45,46,53}$ Tobacco smoke contains many substances that can activate DCs either directly or indirectly by triggering the release of danger signals and pro-inflammatory mediators from resident lung cells, which could be sensed by a wide range of DC-expressed receptors (Table 1). Bioactive endotoxin is present in mainstream and sidestream smoke particles and has been recognized for its strong adjuvant properties on cells of innate immunity. ${ }^{73}$ Interestingly, DC activation after cigarette smoke inhalation is markedly reduced in the absence of the endotoxin-sensing receptor, TLR $4 .{ }^{46}$ Moreover, the entire inflammatory response in the lung after acute and subacute cigarette smoke exposure was shown to rely on intact

\section{Table 1 List of potentially DC-activating and Th2-skewing factors present in tobacco smoke itself or released by tobacco smoke-exposed pulmonary tissue}

\begin{tabular}{|c|c|c|}
\hline \multirow{3}{*}{$\begin{array}{l}\text { Tobacco smoke- } \\
\text { derived } \\
\text { compounds }\end{array}$} & $\begin{array}{l}\text { Endotoxin-like } \\
\text { compounds }\end{array}$ & Ref. $^{73}$ \\
\hline & Aluminium & Ref. ${ }^{107}$ \\
\hline & $\begin{array}{l}\text { Reactive oxygen } \\
\text { species (ROS) }\end{array}$ & Refs. ${ }^{66,92,93}$ \\
\hline \multirow[t]{3}{*}{$\begin{array}{l}\text { Bystander cell- } \\
\text { derived inflamma- } \\
\text { tory mediators with } \\
\text { strong DC-activa- } \\
\text { tion potential }\end{array}$} & $\begin{array}{l}\text { ROS: peroxides, } \\
\text { superoxide anions, } \\
\text { lipid-peroxidation } \\
\text { products (acrolein, } \\
\text { 4-HNE...), and pro- } \\
\text { tein-carbonylation } \\
\text { products }\end{array}$ & Refs. ${ }^{66,92-94}$ \\
\hline & $\begin{array}{l}\text { Danger signals: } \\
\text { Hsp, HMGB1, } \\
\text { ATP, uric acid, and } \\
\text { hyaluronic acid }\end{array}$ & $\begin{array}{l}\text { Refs. }^{74,77,78,83,85,86,} \\
108,112\end{array}$ \\
\hline & $\begin{array}{l}\text { Cytokines: IL-1 } 1 \text {, } \\
\text { TNF- } \alpha, \text { IL-6, GM- } \\
\text { CSF, and TSLP }\end{array}$ & Refs. ${ }^{90,137,163}$ \\
\hline \multirow[t]{5}{*}{$\begin{array}{l}\text { Factors with known } \\
\text { function in Th2 } \\
\text { skewing }\end{array}$} & $\begin{array}{l}\text { Cytokines: GM- } \\
\text { CSF, TSLP, VEGF, } \\
\text { and IL-33 }\end{array}$ & Refs. ${ }^{115,133,135,138}$ \\
\hline & ROS?: isoprostanes & \\
\hline & $\begin{array}{l}\text { Danger signals: } \\
\text { ATP and uric acid }\end{array}$ & Refs. ${ }^{108,112}$ \\
\hline & $\begin{array}{l}\text { Lipids: LTB4, cysLT } \\
\text { and PGE } 2\end{array}$ & Refs. ${ }^{140,142,145,146}$ \\
\hline & Histamine & Ref. 150 \\
\hline
\end{tabular}


TLR4 signaling and its adapter molecule MyD88, illustrating the importance of exogenous or endogenous TLR4 agonists. ${ }^{46,74}$ Cigarette smoke extract, for instance, increased the expression of TLR4 on airway epithelial cells in vitro and induced their activation, a process that can indirectly activate the underlying DC network. ${ }^{75}$ Heat-shock proteins, released by injured or dying cells, can additionally bind TLRs (TLR2 and TLR4) as well as other surface receptors, such as CD91, CD40, and CCR5, thereby initiating a signal transduction cascade leading to immune cell activation. ${ }^{76}$ Smoking has been associated with the release of the $70-\mathrm{kDa}$ heat-shock protein in the lung and by human monocytes and lung fibroblasts in vitro. ${ }^{74,77,78}$ Signaling through the RAGE system (receptor for advanced glycosylation end products) has been implicated in the recruitment, maturation, and migration of DCs to the draining LNs. ${ }^{79,80}$ Expression of RAGE and its major pro-inflammatory ligands was markedly upregulated during smoke-related airway disease on epithelial cells and inflammatory cells, including macrophages and airway DCs. ${ }^{81,82}$ RAGE ligands include advanced glycation end products, which can be produced by non-enzymatic glycation and oxidation of protein and lipids, potentially driven by tobacco smoke exposure and inflammatory stress. Another ligand for RAGE is the nuclear protein high-mobility group box-1 (HMGB1), which is normally buried deep within the nucleus and can be released into the extracellular space by passive diffusion from necrotic cells or by active secretion from activated macrophages/monocytes. ${ }^{83}$ In addition, HMGB1 is a known ligand for TLR2 and TLR $4 .{ }^{84}$ However, HMBG1 release by cigarette smoking has not been explored yet. Extracellular matrix breakdown products from injured or inflamed tissues have also been identified as potent endogenous danger signals. Low molecular weight fragmentation products of the polysaccharide hyaluronic acid were shown to activate DCs and macrophages by engaging TLR2 and TLR4. ${ }^{85,86}$ Hyaluronic acid is degraded by cigarette smoking through oxidative mechanisms. ${ }^{87}$ Also, degradation products of heparan sulfate, ubiquitously present on cell surfaces and extracellular matrix, can activate DCs in vitro. ${ }^{88}$ In addition, the autoimmune response to elastin fragments, which develops after chronic tobacco smoking, points to a certain immunogenic activity of elastin-degradation products on DC-mediated adaptive immunity. ${ }^{89}$ Next to danger signals, pro-inflammatory cytokines and chemokines can additionally target the DC network and regulate their cellular activation status. Tobacco smoke triggers the production of the early response cytokines, tumor necrosis factor- $\alpha$, IL-1 $\beta$, IL- 6 , and granulocyte macrophage colony-stimulating factor (GM-CSF), by bronchial epithelial cells (reviewed in ref. ${ }^{90}$ ). These cytokines are known for their strong DC-maturing properties in vitro.

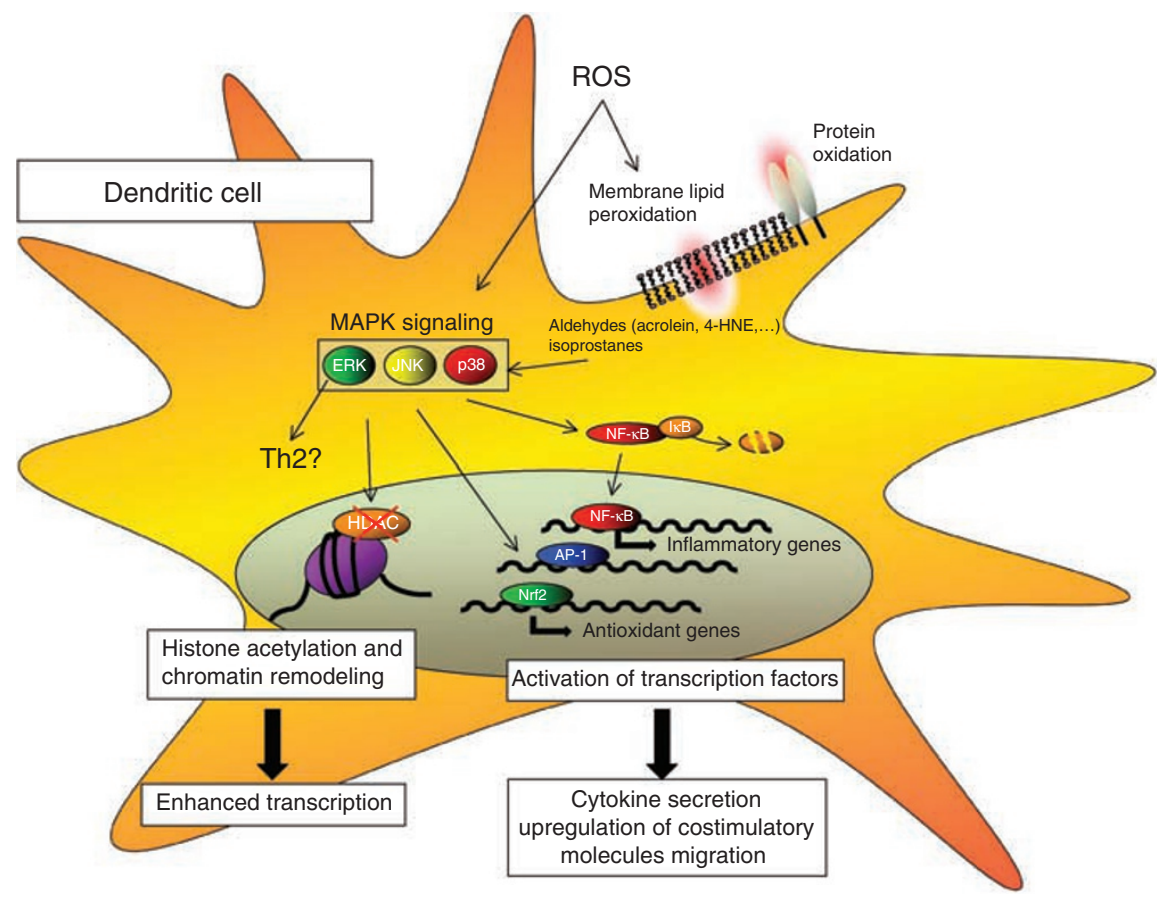

Figure 3 Model for the impact of reactive oxygen species on the intracellular pathways involved in dendritic cell activation. Reactive oxygen species (ROS) interact with proteins and lipids present on the cell membrane, causing cell injury or leading to the formation of highly reactive metabolites, such as acrolein, 4-hydroxy-2-nonenal (4-HNE), and isoprostanes. These lipid peroxidation products are involved in the expression of genes regulating a variety of cellular pathophysiologic activities through various mechanisms: activation of the redox-sensitive transcription factors NF- $\kappa B$ and $A P-1$; phosphorylation of mitogen-activated protein kinases (MAPK) signal transduction pathways, including extracellular signal-regulated kinase (ERK), c-Jun N-terminal kinase (JNK), and p38 kinase, leading to increased gene transcription; chromatin remodeling through the inhibition of histone deacetylase (HDAC) enzymes thereby uncoiling the DNA and allowing increased accessibility for transcription factors. As a result, transcription of multiple inflammatory genes leads to cytokine secretion, upregulation of costimulatory molecules, and DC migration. At the same time, several antioxidant defense mechanisms regulated by the transcription factor nuclear erythroid 2 p45-related factor 2 (Nrf2) are activated. Specific activation of the ERK/MAPK signaling pathway has been linked with changes in DC function that induce Th2 differentiation. AP-1, activator protein-1; DC, dendritic

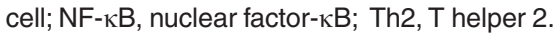


The impact of oxidative stress on pulmonary DC biology represents an interesting, yet unexplored, research area, especially in the context of tobacco smoking. Oxidative stress is responsible for many inflammatory responses in the lung and plays an important role in the pathogenesis of COPD. ${ }^{66,91-93}$ Tobacco smoke contains many reactive oxygen species (ROS), which can overwhelm the lung's natural antioxidant defense mechanisms in the epithelial lining fluid and target underlying airway tissues, including the subepithelial DC network. Together with endogenously released ROS by inflammatory and lung structural cells as a result of tissue inflammation, the increased burden of oxidants in the lung contributes to the oxidative damage of lipids, proteins, and DNA in the lung. This might cause a direct cell injury or induce a variety of cellular responses through the generation of secondary metabolic reactive species (Figure 3). Membrane lipid peroxidation products, for instance, are involved in many of the pathophysiological effects associated with oxidative stress in cells and tissues. These inflammatory lipid mediators have a high affinity toward specific amino-acid residues of intracellular proteins involved in several aspects of cell signaling, chromatin remodeling, and gene expression. ${ }^{94}$ Redox-sensitive activation of the transcription factors, nuclear factor- $\kappa \mathrm{B}$ and activator protein-1, switches on multiple proinflammatory genes in a number of pulmonary cells. Oxidants trigger mitogen-activated protein (MAP) kinase signaling pathways, which are, in turn, involved in the maturation of DCs and secretion of pro-inflammatory cytokines.$^{95}$ Moreover, oxidative stress can alter histone acetylation/deacetylation processes, allowing transcription factors to access DNA and start inflammatory gene transcription (discussed below). The importance of oxidative pathways in the activation of DCs by cigarette smoke was recently shown by Vassallo et al. ${ }^{96}$ They showed that cigarette smoke-conditioned DCs and DCs from cigarette smokeexposed mice produced high levels of neutrophil-attracting cytokines that could be suppressed by the antioxidant $\mathrm{N}$-acetyl cysteine. The involvement of oxidative stress mechanisms in DC activation and cytokine secretion includes a significant increase in protein oxidation-measured by the formation of carbonyl radicals-and triggers p38 and extracellular signal-regulated kinase/mitogen-activated protein kinase (ERK/MAPK) signaling, resulting in the upregulation of $\mathrm{CD} 40 .{ }^{97} \mathrm{In}$ addition, the modification of extracellular matrix proteins by reactive carbonyls triggers macrophage accumulation, adhesion, and activation through scavenger receptors, which are also abundantly expressed on DCs. ${ }^{98}$ On the other hand, scavenger receptors inhibit DC emigration to the LNs and the subsequent development of allergic inflammation, ${ }^{99}$ illustrating the complexity of pro- vs. anti-inflammatory cellular events following oxidative stress in the lung.

The pleiotropic effects of tobacco smoke on the immunostimulatory function of DCs are further illustrated by a study reporting a diminished capacity of DCs from cigarette smoke-exposed mice to induce IL-2 production by T cells, which was associated with a decreased antigen-specific T-cell proliferation in vivo. ${ }^{49}$ Moreover, in vitro incubation of human monocyte-derived DCs with cigarette smoke extract suppressed the lipopoly- saccharide-induced upregulation of CD40, CD80, CD86, and CCR7. ${ }^{100}$ Also, DCs isolated from the lungs of smoke-exposed mice produce more tumor necrosis factor- $\alpha$, but less IL-12, when stimulated ex vivo. ${ }^{101}$ Decreased production of IL-12p70 by cigarette smoke extract-conditioned DCs prevents priming of Th1 cells, with a deviation of the response toward Th2. By contrast, the generation of neutrophilic cytokines, intracellular levels of cyclooxygenase-2, and the production of prostaglandin $(\mathrm{PG}) \mathrm{E}_{2}$ were enhanced after the incubation of DCs with cigarette smoke extract.

\section{COULDTOBACCO SMOKE EXPOSURETRIGGER A DC- DEPENDENTTH2 SENSITIZATION?}

Tobacco smoke components thus appear to act as prototypical triggers of innate immune responses. DCs, by integrating key functions of innate and adaptive immunity, arise as the perfect "missing link" explaining the induction of a T-cell-driven allergic inflammation following tobacco smoke inhalation. We are proposing several candidate pathogenetic mechanisms, which all converge on the pulmonary DCs and interact within the complex cellular and molecular environment which is the lung (Figure 4).

\section{Direct pro-allergic effects of tobacco smoke through DCs}

First, tobacco smoke itself might contain the putative DC-targeted pro-allergic trigger. As already mentioned, biologically active endotoxin present in cigarette smoke could act as an adjuvant in airway sensitization through TLR4 signaling. ${ }^{73}$ By engaging TLR4, trace amounts of endotoxin were able to break tolerance toward co-inhaled ovalbumin (OVA), resulting in OVA-specific allergic airway inflammation in mice. ${ }^{102}$ This phenomenon was associated with the activation and enhanced migration of airway DCs. ${ }^{103}$ Another possibility involves TLR2, which, when engaged on DCs, can result in the induction of Th2 responses in the lung. ${ }^{104,105}$ TLR2 recognizes not only peptidoglycans from Gram-positive bacteria and bacterial lipopeptides, but also endogenous danger signals, such as $70-\mathrm{kDa}$ heat-shock protein (the latter is known to be released in smoke-exposed airways ${ }^{104}$ ). In addition to TLRs, the TLR-signaling adaptor molecule, MyD88, has been recognized as a crucial component in the induction of adaptive $\mathrm{Th} 2$ responses toward allergens. ${ }^{106}$ It would therefore be interesting to evaluate the importance of these TLRs and MyD88 in the context of tobacco smoke-induced airway sensitization.

In addition to endotoxin, aluminum has been detected at high concentrations in tobacco smoke formulations, raising the idea of alum-like hydroxyl salts potentially precipitating in the epithelial lining fluid overlying the DC network. ${ }^{107}$ Alum is routinely used as an adjuvant in human and animal vaccines, and is recognized for its strong Th2-skewing properties when administered in combination with allergens. Alum was recently shown to mediate its Th2 adjuvant effects through the local release of uric acid, an endogenous danger signal, followed by the accumulation of inflammatory DCs and induction of strong Th2 responses in draining LNs. ${ }^{108}$ Alternatively, alum can activate the Nalp3-inflammasome complex, a major intracellular innate 
Mechanisms of allergic sensitization by tobacco smoke

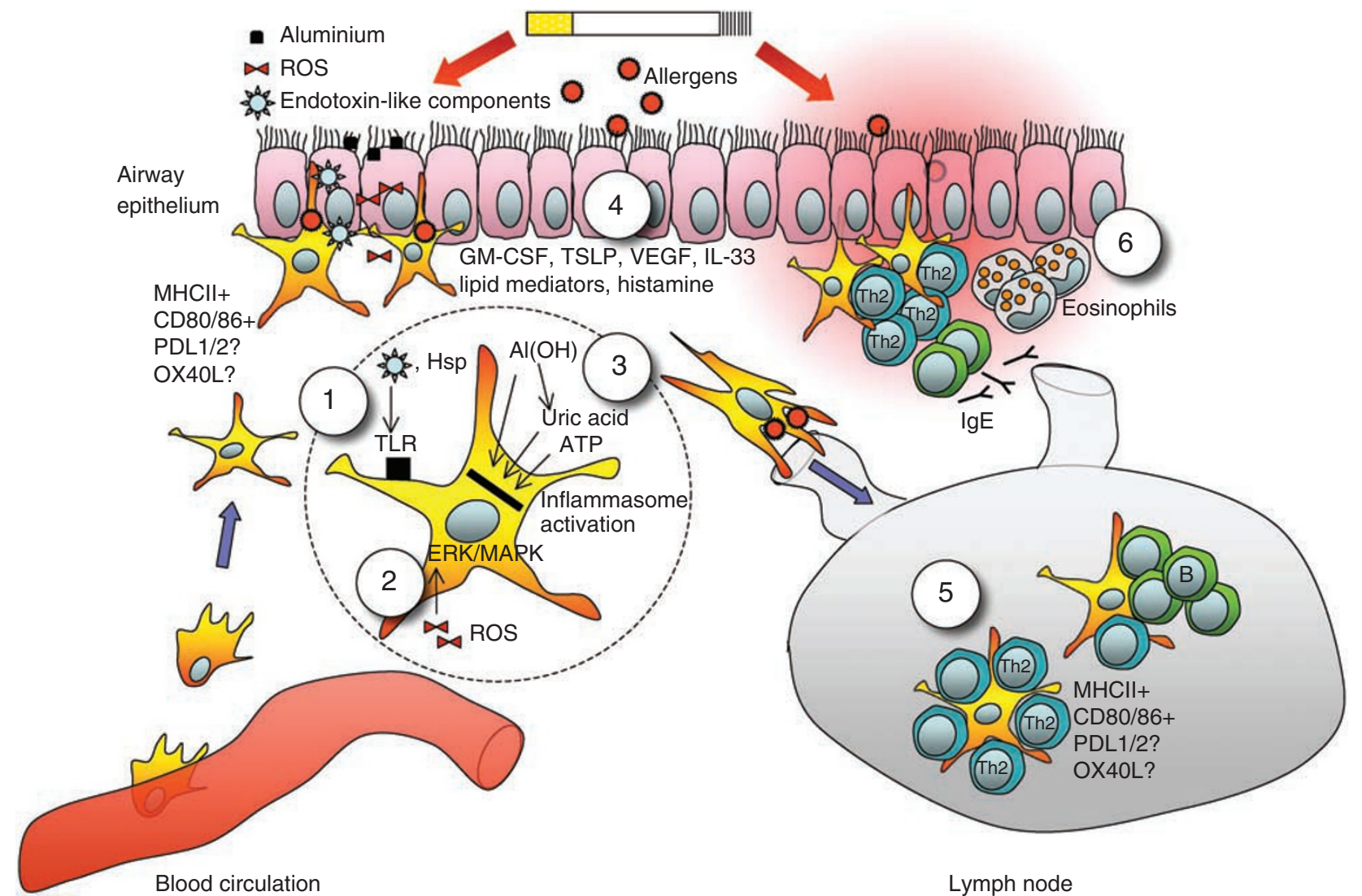

Figure 4 Potential mechanisms of allergic sensitization by tobacco smoke toward co-inhaled allergens with emphasis on the central role of the pulmonary DC. Increased numbers of DCs recruited toward the airways upon the combined challenge with tobacco smoke and allergens interact with innate immune triggers present in the tobacco smoke itself or released by the epithelial environment. (1) Endotoxin-like compounds can induce TLR activation in DCs. Heat-shock proteins (Hsps), released as danger signals upon cellular stress, can also interact with TLRs on DCs. (2) Reactive oxygen species (ROS) can interfere with redox-sensitive pathways in DCs and airway epithelial cells and modulate cellular activation and cytokine secretion. Activation of the ERK/MAPK signaling pathway in DCs can alter DC function in a way that leads to preferential priming of Th2 cells. (3) Aluminium present in tobacco smoke could precipitate as hydroxy salts in the epithelial lining fluid and trigger activation of the inflammasome pathway directly, or through local release of the danger molecule, uric acid. The nucleotide ATP represents another danger signal that when released from stressed or damaged cells activates the inflammasome complex. (4) Pro-inflammatory cytokines produced by epithelial cells or mast cells in close proximity to airway DCs have the capacity to further modulate DC-mediated immune responses. These cytokines include the growth factors, GM-CSF, TSLP, and VEGF, and the IL-1 family member, IL-33. Lipid mediators, such as prostaglandins and leukotrienes, and the mast-cell product histamine might play a role as well. (5) As a result, DCs emanating from a cigarette smoke-conditioned pulmonary environment instruct naive T cells in draining LNs toward a Th2 response against co-inhaled innocuous antigen. (6) The ensuing allergic response is characterized by infiltrating Th2 effector cells, which produce Th2-specific cytokines, such as IL-4, IL-5, and IL-13, followed by allergen-specific IgE production and eosinophil accumulation in the lung. DC, dendritic cell; GM-CSF, granulocyte macrophage colony-stimulating factor; LN, lymph node; MAPK, mitogen-activated protein kinases; Th2, T helper 2; TLR, Toll-like receptor; VEGF, vascular endothelial growth factor.

immune response system. ${ }^{109}$ Activation of the inflammasome is responsible for the generation of active caspase- 1 , which cleaves a number of pro-inflammatory cytokines into their bio-active form, including IL-1 $\beta, \mathrm{IL}-18$, and IL-33. The inflammasome pathway is emerging as an important pathway in the induction of Th2 responses in lung. Nalp3 inflammasome assembly and activation can occur as a result of purinergic receptor triggering by extracellular ATP. ${ }^{10,111}$ Extracellular ATP has recently been discovered as a potent danger signal for DCs, triggering purinergic receptor on airway DCs and leading to a DC-dependent allergic sensitization toward the co-inhaled inert protein. ${ }^{112}$ Endogenous sources of extracellular ATP comprise stressed or death cells as a result of pulmonary inflammation, including asthma and COPD. ${ }^{113,114}$ The involvement of extracellular ATP and uric acid and the activation of the Nalp3-inflammasome complex in the abrogation of inhalational tolerance and induction of aberrant Th2-driven inflammation by cigarette smoke represents an interesting working hypothesis for further investigation. As mentioned, the activation of the inflammasome triggers the production of IL-33, an IL-1 family member that was recently discovered to interact with the orphan receptor ST2, preferentially expressed on Th2 cells and mast cells. ${ }^{115}$ Mainly produced by lung epithelial cells, IL-33 drives the expression of Th2-associated cytokines, ultimately leading to pathological changes in mucosal organs. The pro-inflammatory properties of IL-33 are mediated through the recruitment and activation of Th2 
lymphocytes and mast cells, and its biological activity was shown to cooperate with that of thymic stromal lymphopoietin (TSLP) (see below). ${ }^{115-117}$ Less explored, but perhaps more relevant, is the critical involvement of a DC-expressed ST2 ligand in the triggering of allergic airway primo-sensitization. ${ }^{32}$ It will be interesting to learn if, and at what stage, IL-33 is expressed during the course of cigarette smoke-induced lung inflammation and to what extent it initiates or amplifies a pro-allergic setting.

Another cytokine with an emerging role in allergic airway disease and smoke-induced COPD is IL-17. It is the product of Th17 cells, a recently discovered Th-cell subset involved in the pathogenesis of chronic tissue inflammation. Levels of IL17 are increased in the lungs of asthmatic and allergic mice, in which it regulates neutrophil recruitment. ${ }^{118}$ In mice, Th17 cells have been shown to cooperate with Th2 cells to enhance antigen-induced eosinophil recruitment into the airways and airway hyper-responsiveness. ${ }^{119}$ It appears that DCs are able to provide the Th17-inducing cytokine, IL-6, during initial Th17cell priming. In addition, DCs are potent producers of the IL-12 cytokine family member, IL-23 (or IL-17E), which is necessary to maintain the Th17 phenotype and represents a strong activator of Th17 effector function. Interestingly, chronic smoke exposure triggers progressive infiltration of Th17 cells into the airways. ${ }^{120}$ Thus, chronic smoke exposure could program airway DCs to install an aberrant Th17-oriented climate conducive to subsequent allergic sensitization to the inhaled antigen. On the other hand, the introduction of smoke exposure on a background of already established chronic allergic airway inflammation did not seem to induce a Th17 response. ${ }^{121}$

As mentioned earlier, cigarette smoke is a notorious vehicle for ROS. The redox equilibrium of DCs has been shown to determine the outcome of T-cell polarization, implicating that ROS and their metabolic intermediates might be involved in allergic sensitization. ${ }^{122,123}$ Activation of different MAPK signaling pathways in DCs has been shown to "rewire" the Thelper-skewing properties of this cell. ${ }^{95}$ Relative activation levels of the ERK/MAPK signaling pathway determine the ability of DCs to instruct Th2-cell differentiation in response to stimuli such as TLR2 agonists and schistosoma egg antigens. ${ }^{124,125}$ The ERK/MAPK signaling pathway negatively regulates the phenotypical and functional maturation of DC in response to Th1 stimuli by suppressing IL-12 production. ${ }^{126}$ The oxidative stress-mediated ERK/MAPK phosphorylation and c-Fos activity in DCs after incubation with cigarette smoke extract in vitro strongly suggest a role for ROS in smoke-induced Th2 skewing of immune responses. ${ }^{101}$ Interestingly, the deletion of the antioxidant gene transcription factor, nuclear erythroid $2 \mathrm{p} 45$ related factor-2 (Nrf2), in DCs leads to oxidative stress in DCs and an enhanced responsiveness of DCs to airborne particulate matter that was characterized by a Th2-biased antigen-specific immune response. ${ }^{127}$ It would be worth exploring the extent to which Nrf2 conveys protection to DCs in response to pro-oxidative cigarette smoke and allergen sensitization. Disruption of Nrf2 has already been shown to aggravate exacerbations of asthma and the severity of lung inflammation in response to cigarette smoke. ${ }^{128,129}$ Finally, isoprostanes are stable metabolites resulting from the oxidative transformation of arachidonic acid metabolites and known biomarkers for oxidative stress in lung inflammatory diseases, such as asthma and COPD. Their biochemical analogs in plants, termed phytoprostanes, are present as residues in pro-allergic pollen extracts and were shown to modulate human DC function in vitro in a way that favors Th2-cell polarization. ${ }^{130}$

\section{Indirect effects of tobacco smoke on DCs}

Disruption of the bronchial epithelial cell homeostasis has been shown to initiate the inflammatory cascade that leads to the development of asthma (reviewed in ref. ${ }^{25}$ ). Cigarette smoke is, for instance, able to cleave airway epithelial tight junctions. ${ }^{131}$ The resulting increase in epithelial permeability could lead to enhanced penetration of airborne antigen and promote the activation of the subepithelial DC network. ${ }^{132}$ Disruption of the interepithelial adhesion barrier can additionally promote the activation of the bronchial epithelial cells and result in the release of danger signals and inflammatory cytokines. Several of these epithelial-cell-derived factors are known to be endowed with a strong Th2-inducive capacity in the lung. Bronchial expression of GM-CSF was sufficient to overcome the tolerogenic response toward inhaled antigens and initiate pro-allergic Th2 responses. ${ }^{133}$ Transgenic expression of GM-CSF in the lung promoted the differentiation and activation of a myeloid DC population, from which the majority was localized in the airway epithelium and peribronchial/perivascular areas. ${ }^{134}$ Importantly, increased levels of GM-CSF have been found in the lungs of smoke-sensitized mice, and the allergic sensitization by cigarette smoking was, at least partially, GM-CSF dependent. ${ }^{17-19}$ TSLP, an IL-7-like growth factor, has more recently been studied for its non-redundant role in the development of allergic responses, not only through the upregulation of OX40-L on DCs and polarization of immune responses, but also by interacting with Th2 cells. ${ }^{135}$ Very recently, Nakamura et al. ${ }^{136}$ showed that intranasal administration of cigarette smoke extract-induced TSLP expression in the mouse lung and that blocking TSLP activity inhibited OVA-specific Th2 responses and airway inflammation after concomittant cigarette smoke and OVA exposure. Interestingly, smooth muscle cells of COPD patients displayed stronger TSLP immunoreactivity than normal subjects. ${ }^{137}$ Vascular endothelial growth factor (VEGF), a multifunctional mediator of vascular and extravascular remodeling and inflammation, was discovered to enhance antigen sensitization and was crucial in adaptive Th2 inflammation. ${ }^{138}$ Lung-specific transgenic expression of VEGF induced, next to angiogenesis, edema, inflammation, vascular and parenchymal remodeling, a marked Th2 sensitization towards a model allergen, OVA. This was mainly attributed to epithelial and Th2-cell-derived VEGF. Importantly, in vitro studies using cell lines representing bronchial and alveolar epithelium have shown that VEGF expression is increased in response to cigarette smoke exposure. ${ }^{139}$ Although VEGF release upon smoking is mainly aimed at maintaining tissue homeostasis and alveolar structure, ${ }^{90}$ its aberrant expression in larger airways might alternatively contribute to allergen sensitization. 
Lipid mediators, such as leukotrienes and prostanoids, are formed in response to various noxious stimuli in the lung, such as cigarette smoke, and regulate a broad range of physiological and pathological processes that can further tweak Th2 responses. Leukotriene (LT) B4 from lung epithelial cells and fibroblasts conditioned with cigarette smoke extracts attracts monocytes and DCs in vitro. ${ }^{62,63}$ The expression of its receptor, BLT1, on DCs is necessary for the development of Th2 responses in an allergy mouse model, irrespective of the maturation status of these DCs. ${ }^{140}$ As LTB4 represents an important mediator in both the COPD and asthma pathology, its overexpression during tobacco smoking might provide an additional link between smoking and allergen sensitization. ${ }^{66,141}$ Other LTs, such as cysteinyl LTs (cysLTs), have been well documented in asthmatic lung disorders in which they potentiate DC function in an early stage of antigen-specific immune responses. ${ }^{142}$ The role of cysLTs in the pathogenesis of COPD is, however, debated. At least one study has suggested an enhanced biosynthesis of cysLTs in smokers. ${ }^{143}$ Another class of lipid mediators, the PGs, is known for its pleiotropic effects on immunological processes through the modulation of DC function. ${ }^{144} \mathrm{PGE}_{2}$ is known to influence $\mathrm{DC}$ behavior in a way that favors Th2-cell differentiation. ${ }^{145,146} \mathrm{PGE}_{2}$ is increased in the airways of smokers and COPD patients in whom it exerts not only beneficial effects, through bronchodilatation and immunosuppression, but also negative effects by enhancing mucus secretion. ${ }^{66}$ In addition, $\mathrm{PGE}_{2}$ is produced by DCs themselves in response to cigarette smoke extract in vitro in which it preferentially primes Th2 cells by acting in an autocrine way. ${ }^{96,100}$

Finally, Mast cells reside in the same anatomical niche as DCs and smoking is associated with an increase in mast cell numbers in the bronchial mucosa. ${ }^{147}$ Very likely, cigarette smoking could also trigger mast cell activation and degranulation, ${ }^{148,149}$ and this may favor Th2 priming through interaction with airway DCs. Indeed, histamine released by activated mast cells suppressed IL-12p70 production by DCs and favored Th2 polarization in vitro. ${ }^{150}$ Mast-celldegranulation products, such as histamine, lipid mediators, and spingosine-1-phosphate, can activate immature DCs, trigger their mobilization to draining LNs, and induce the preferential priming of Th2 cells. ${ }^{151-153}$ In addition, mast cells are significant sources of TSLP, which potently enhances allergic sensitization. ${ }^{154}$

\section{Epigenetic reprogramming of DCs}

The term "epigenetics" describes heritable changes in phenotype or gene expression that are not encoded by DNA sequences themselves. Diverse cellular functions, including the regulation of inflammatory gene expression, DNA repair, and cell proliferation, are regulated by changes in DNA methylation, covalent histone modifications, and microRNA expression patterns. Over the past years, it has become clear that epigenetic modifications of cell function play an important role in airway diseases, such as asthma and COPD. Among environmental agents, tobacco smoke is notoriously active in inducing epigenetic DNA modifications. Also, epidemiological and experimental studies suggest that asthma risk may be influenced by environmentally induced epigenetic changes of genes critical to Th-cell differentiation. ${ }^{155}$ Epigenetic control of inflammation in the lung has been observed by post-translational histone acetylation, allowing unwinding of the chromatin structure and an enhanced transcription of pro-inflammatory genes. Conversely, chromatin condensation and hence shutdown of gene transcription is promoted by a whole family of histone deacetylases (HDACs). Strikingly, both asthma and COPD are associated with a reduced HDAC activity in bronchial biopsies, lung parenchyma, and alveolar macrophages. ${ }^{156}$ In addition, alveolar macrophages from smokers show reduced HDAC activity and expression of HDAC2. ${ }^{156}$ It has been proposed that oxidative stress can inactivate HDAC2 by means of nitration or carboxylation and that HDAC2 is phosphorylated, ubiquitinated, and degraded as a consequence of cigarette smoke exposure. ${ }^{157,158}$ In the presence of inflammatory stimuli, HDACs appear capable of deacetylating histones in chromatin regions containing pro-inflammatory genes and shut down their expression. Hence, a loss of HDAC activity removes the "breaks" for pro-inflammatory gene expression and also leads to a corticoid-resistant inflammatory phenotype. ${ }^{159}$ Interestingly, the pharmacological inhibition of HDAC in DCs was shown to alter the Th1/Th2 balance in vitro through enhanced expression of indoleamine 2, 3-dioxygenase in DCs, inhibition of IL-12p40 production, and defects in DC-controlled Th1-effector-cell activation. ${ }^{160-162}$ Possibly, epigenetic reprogramming of DCs driven by oxidative stress after tobacco smoke exposure could favor a Th2 bias toward concurrently inhaled antigens. The contribution of DC epigenetic reprogramming in the outcome of immune or inflammatory response is indeed a fascinating area for further research.

\section{CONCLUSION}

Airway DCs emerge as central players in the initial recognition of allergens and in the decision between the establishment of inhalational tolerance and allergen sensitization. The effects of tobacco smoke on DC biology, especially its strong adjuvant potential on the subepithelial DC network, suggest that an aberrant DC function might underlie the allergic sensitization observed toward concurrently inhaled antigens during smoking. We have discussed a variety of innate immune pathways and mediators that could trigger inappropriate DC activation and induce a local inflammatory context conducive to the development of allergen-specific Th2 cells. Importantly, these triggers of innate immunity could be delivered by the tobacco smoke itself or, alternatively, released by damaged lung epithelia and other pulmonary cells in response to tobacco smoking. This immunopathological model perfectly illustrates the role of airway DCs as central regulators of pulmonary allergic responses by integrating signals from the environment and resident cells. In an era in which the treatment of asthma is still dominated by the hegemony of glucocorticosteroids, exploiting this knowledge may lead to novel, more targeted therapeutic approaches.

\section{ACKNOWLEDGMENTS}

This study was supported by grants from the Concerted Research Initiative Ghent University (BOF/GOA 12050698 and BOF/GOA 12.515.04), Interuniversity Attraction Poles Program (Belgian State, Belgian Science Policy, Project P6/35), and FWO Flanders (Project 3G.0052.06). 


\section{DISCLOSURE}

The authors declared no conflict of interest.

(C) 2009 Society for Mucosal Immunology

\section{REFERENCES}

1. Wills-Karp, M. Immunologic basis of antigen-induced airway hyperresponsiveness. Annu. Rev. Immunol. 17, 255-281 (1999).

2. Thomson, N.C., Chaudhuri, R. \& Livingston, E. Asthma and cigarette smoking. Eur. Respir. J. 24, 822-833 (2004).

3. Gilmour, M.I., Jaakkola, M.S., London, S.J., Nel, A.E. \& Rogers, C.A. How exposure to environmental tobacco smoke, outdoor air pollutants, and increased pollen burdens influences the incidence of asthma. Environ. Health Perspect. 114, 627-633 (2006).

4. Lazarus, S.C. et al. Smoking affects response to inhaled corticosteroids or leukotriene receptor antagonists in asthma. Am. J. Respir. Crit. Care Med. 175, 783-790 (2007).

5. Thomson, N.C. \& Spears, M. The influence of smoking on the treatment response in patients with asthma. Curr. Opin. Allergy Clin. Immunol. 5, 57-63 (2005).

6. Kumar, R. Prenatal factors and the development of asthma. Curr. Opin. Pediatr. 20, 682-687 (2008).

7. Raherison, C. et al. Smoking exposure and allergic sensitization in children according to maternal allergies. Ann. Allergy Asthma Immunol. 100, 351-357 (2008).

8. Noakes, P.S., Holt, P.G. \& Prescott, S.L. Maternal smoking in pregnancy alters neonatal cytokine responses. Allergy 58, 1053-1058 (2003).

9. Gentile, D., Howe-Adams, J., Trecki, J., Patel, A., Angelini, B. \& Skoner, D. Association between environmental tobacco smoke and diminished dendritic cell interleukin 10 production during infancy. Ann. Allergy Asthma Immunol. 92, 433-437 (2004).

10. Gilliland, F.D. et al. Regular smoking and asthma incidence in adolescents. Am. J. Respir. Crit. Care Med. 174, 1094-1100 (2006).

11. Plipari, R., Jaakkola, J.J., Jaakkola, N. \& Jaakkola, M.S. Smoking and asthma in adults. Eur. Respir. J. 24, 734-739 (2004).

12. Seymour, B.W., Pinkerton, K.E., Friebertshauser, K.E., Coffman, R.L. \& Gershwin, L.J. Second-hand smoke is an adjuvant for T helper-2 responses in a murine model of allergy. J. Immunol. 159, 6169-6175 (1997).

13. Moerloose, K.B., Pauwels, R.A. \& Joos, G.F. Short-term cigarette smoke exposure enhances allergic airway inflammation in mice. Am. J. Respir. Crit. Care Med. 172, 168-172 (2005)

14. Robbins, C.S. et al. Mainstream cigarette smoke exposure attenuates airway immune inflammatory responses to surrogate and common environmental allergens in mice, despite evidence of increased systemic sensitization. J. Immunol. 175, 2834-2842 (2005).

15. Melgert, B.N. et al. Short-term smoke exposure attenuates ovalbumininduced airway inflammation in allergic mice. Am. J. Respir. Cell Mol. Biol. 30, 880-885 (2004)

16. Thatcher, T.H., Benson, R.P., Phipps, R.P. \& Sime, P.J. High dose but not low dose mainstream cigarette smoke suppresses allergic airway inflammation by inhibiting T cell function. Am. J. Physiol. Lung Cell Mol. Physiol. 295, L412-L421 (2008).

17. Moerloose, K.B., Robays, L.J., Maes, T., Brusselle, G.G., Tournoy, K.G. \& Joos, G.F. Cigarette smoke exposure facilitates allergic sensitization in mice. Respir. Res. 7, 49 (2006).

18. Trimble, N.J., Botelho, F.M., Bauer, C.M., Fattouh, R. \& Stampfli, M.R. Adjuvant and anti-inflammatory properties of cigarette smoke in murine allergic airway inflammation. Am. J. Respir. Cell Mol. Biol. 40, 38-46 (2009).

19. Rumold, R., Jyrala, M. \& Diaz-Sanchez, D. Secondhand smoke induces allergic sensitization in mice. J. Immunol. 167, 4765-4770 (2001).

20. Vermaelen, K.Y. et al. Matrix metalloproteinase-9-mediated dendritic cell recruitment into the airways is a critical step in a mouse model of asthma. J. Immunol. 171, 1016-1022 (2003).

21. Bowles, K. et al. Exposure of adult mice to environmental tobacco smoke fails to enhance the immune response to inhaled antigen. Inhal. Toxicol. 17, 43-51 (2005).

22. Van Hove, C.L., Moerloose, K., Maes, T., Joos, G.F. \& Tournoy, K.G. Cigarette smoke enhances Th-2 driven airway inflammation and delays inhalational tolerance. Respir. Res. 9, 42 (2008).
23. Holt, P.G. \& Stumbles, P.A. Regulation of immunologic homeostasis in peripheral tissues by dendritic cells: the respiratory tract as a paradigm. J. Allergy Clin. Immunol. 105, 421-429 (2000).

24. Vermaelen, K. \& Pauwels, R. Pulmonary dendritic cells. Am. J. Respir. Crit. Care Med. 172, 530-551 (2005).

25. Hammad, H. \& Lambrecht, B.N. Dendritic cells and epithelial cells: linking innate and adaptive immunity in asthma. Nat. Rev. Immunol. 8, 193-204 (2008).

26. Jahnsen, F.L. et al. Accelerated antigen sampling and transport by airway mucosal dendritic cells following inhalation of a bacterial stimulus. J. Immunol. 177, 5861-5867 (2006).

27. Lambrecht, B.N., Prins, J.B. \& Hoogsteden, H.C. Lung dendritic cells and host immunity to infection. Eur. Respir. J. 18, 692-704 (2001).

28. Mizgerd, J.P. Acute lower respiratory tract infection. N. Engl. J. Med. 358, 716-727 (2008)

29. Gallucci, S. \& Matzinger, P. Danger signals: SOS to the immune system. Curr. Opin. Immunol. 13, 114-119 (2001).

30. Lambrecht, B.N. \& Hammad, H. Taking our breath away: dendritic cells in the pathogenesis of asthma. Nat. Rev. Immunol. 3, 994-1003 (2003).

31. Holt, P.G. \& Upham, J.W. The role of dendritic cells in asthma. Curr. Opin. Allergy Clin. Immunol. 4, 39-44 (2004).

32. Lambrecht, B., De Veerman, M., Coyle, A., Gutierrez-Ramos, J., Thielemans, K. \& Pauwels, R. Myeloid dendritic cells induce Th2 responses to inhaled antigen, leading to eosinophilic airway inflammation. J. Clin. Invest. 106, 551-559 (2000).

33. De Heer, H.J. et al. Essential role of lung plasmacytoid dendritic cells in preventing asthmatic reactions to harmless inhaled antigen. J. Exp. Med. 200, 89-98 (2004).

34. van Rijt, L.S. et al. In vivo depletion of lung CD11C+ dendritic cells during allergen challenge abrogates the characteristic features of asthma. J. Exp. Med. 201, 981-991 (2005).

35. Huh, J.C. et al. Bidirectional interactions between antigen-bearing respiratory tract dendritic cells (DCs) and T cells precede the late phase reaction in experimental asthma: DC activation occurs in the airway mucosa but not in the lung parenchyma. J. Exp. Med. 198, 19-30 (2003).

36. Vermaelen, K. \& Pauwels, R. Accelerated airway dendritic cell maturation, trafficking, and elimination in a mouse model of asthma. Am. J. Respir. Cell Mol. Biol. 29, 405-409 (2003).

37. Lambrecht, B., Carro-Muino, I., Vermaelen, K. \& Pauwels, R. Allergeninduced changes in bone-marrow progenitor and airway dendritic cells in sensitized rats. Am. J. Respir. Cell Mol. Biol. 20, 1165-1174 (1999).

38. van Riit, L.S. et al. Allergen-induced accumulation of airway dendritic cells is supported by an increase in CD31 hiLy-6Cneg bone marrow precursors in a mouse model of asthma. Blood 100, 3663-3671 (2002).

39. Akbari, O., DeKruyff, R.H. \& Umetsu, D.T. Pulmonary dendritic cells producing $\mathrm{LL}-10$ mediate tolerance induced by respiratory exposure to antigen. Nat. Immunol. 2, 725-731 (2001).

40. Beaty, S.R., Rose, C.E. \& Sung, S.S. Diverse and potent chemokine production by lung CD11bhigh dendritic cells in homeostasis and in allergic lung inflammation. J. Immunol. 178, 1882-1895 (2007).

41. Sung, S.S., Fu, S.M., Rose, C.E., Gaskin, F., Ju, S.T. \& Beaty, S.R. A major lung CD103 (alphaE)-beta7 integrin-positive epithelial dendritic cell population expressing Langerin and tight junction proteins. J. Immunol. 176, 2161-2172 (2006)

42. Upham, J., Denburg, J. \& O'Byrne, P. Rapid response of circulating myeloid dendritic cells to inhaled allergen in asthmatic subjects. Clin. Exp. Allergy 32, 818-823 (2002).

43. Jahnsen, F., Moloney, E., Hogan, T., Upham, J., Burke, C. \& Holt, P. Rapid dendritic cell recruitment to the bronchial mucosa of patients with atopic asthma in response to local allergen challenge. Thorax 56 , 823-826 (2001).

44. Möller, G.M. et al. Increased numbers of dendritic cells in the bronchial mucosa of atopic asthmatic patients: downregulation by inhaled corticosteroids. Clin. Exp. Allergy 26, 517-524 (1996).

45. D'hulst, A.I., Vermaelen, K.Y., Brusselle, G.G., Joos, G.F. \& Pauwels, R.A. Time course of cigarette smoke-induced pulmonary inflammation in mice. Eur. Respir. J. 26, 204-213 (2005).

46. Maes, T. et al. Murine TLR4 is implicated in cigarette smoke-induced pulmonary inflammation. Int. Arch. Allergy Immunol. 141, 354-368 (2006).

47. Zeid, N.A. \& Muller, H.K. Tobacco smoke induced lung granulomas and tumors: association with pulmonary Langerhans cells. Pathology 27, 247-254 (1995). 
48. Robbins, C.S. et al. Cigarette smoke decreases pulmonary dendritic cells and impacts antiviral immune responsiveness. Am. J. Respir. Cell Mol. Biol. 30, 202-211 (2004).

49. Robbins, C.S., Franco, F., Mouded, M., Cernadas, M. \& Shapiro, S.D. Cigarette smoke exposure impairs dendritic cell maturation and $\mathrm{T}$ cell proliferation in thoracic lymph nodes of mice. J. Immunol. 180, 66236628 (2008).

50. Soler, P., Moreau, A., Basset, F. \& Hance, A.J. Cigarette smokinginduced changes in the number and differentiated state of pulmonary dendritic cells/Langerhans cells. Am. Rev. Respir. Dis. 139, 1112-1117 (1989).

51. Casolaro, M.A., Bernaudin, J.F., Saltini, C., Ferrans, V.J. \& Crystal, R.G. Accumulation of Langerhans' cells on the epithelial surface of the lower respiratory tract in normal subjects in association with cigarette smoking. Am. Rev. Respir. Dis. 137, 406-411 (1988).

52. Hoogsteden, H.C., Verhoeven, G.T., Lambrecht, B.N. \& Prins, J.B. Airway inflammation in asthma and chronic obstructive pulmonary disease with special emphasis on the antigen-presenting dendritic cell: influence of treatment with fluticasone propionate. Clin. Exp. Allergy 29 (Suppl 2), 116-124 (1999).

53. Bratke, K. et al. Function-associated surface molecules on airway dendritic cells in cigarette smokers. Am. J. Respir. Cell Mol. Biol. 38, 655-660 (2008).

54. Tsoumakidou, M. et al. Cigarette smoking alters bronchial mucosal immunity in asthma. Am. J. Respir. Crit. Care Med. 175, 919-925 (2007).

55. Tsoumakidou, M., Demedts, I.K., Brusselle, G.G. \& Jeffery, P.K. Dendritic cells in chronic obstructive pulmonary disease: new players in an old game. Am. J. Respir. Crit. Care Med. 177, 1180-1186 (2008).

56. Bracke, K.R. et al. Cigarette smoke-induced pulmonary inflammation and emphysema are attenuated in CCR6-deficient mice. J. Immunol. 177, 4350-4359 (2006).

57. Demedts, I.K. et al. Accumulation of dendritic cells and increased CCL2O levels in the airways of COPD patients. Am. J. Respir. Crit. Care Med. 175, 998-1005 (2007).

58. Thorley, A.J., Goldstraw, P., Young, A. \& Tetley, T.D. Primary human alveolar type II epithelial cell CCL2O (macrophage inflammatory protein3alpha)-induced dendritic cell migration. Am. J. Respir. Cell Mol. Biol. 32, 262-267 (2005).

59. Schutyser, E., Struyf, S. \& Van Damme, J. The CC chemokine CCL20 and its receptor CCR6. Cytokine Growth Factor Rev. 14, 409-426 (2003).

60. Robays, L.J. et al. Chemokine receptor CCR2 but not CCR5 or CCR6 mediates the increase in pulmonary dendritic cells during allergic airway inflammation. J. Immunol. 178, 5305-5311 (2007).

61. Fuke, S., Betsuyaku, T., Nasuhara, Y., Morikawa, T., Katoh, H. \& Nishimura, M. Chemokines in bronchiolar epithelium in the development of chronic obstructive pulmonary disease. Am. J. Respir. Cell Mol. Biol. 31, 405-412 (2004).

62. Sato, E. et al. Smoke extract stimulates lung fibroblasts to release neutrophil and monocyte chemotactic activities. Am. J. Physiol. 277, L1149-L1157 (1999).

63. Masubuchi, T. et al. Smoke extract stimulates lung epithelial cells to release neutrophil and monocyte chemotactic activity. Am. J. Pathol. 153, 1903-1912 (1998).

64. Castro, P. et al. Inhibition of interleukin-1 beta reduces mouse lung inflammation induced by exposure to cigarette smoke. Eur. J. Pharmacol. 498, 279-286 (2004).

65. Soruri, A., Riggert, J., Schlott, T., Kiafard, Z., Dettmer, C. \& Zwirner, J. Anaphylatoxin C5a induces monocyte recruitment and differentiation into dendritic cells by TNF-alpha and prostaglandin E2-dependent mechanisms. J. Immunol. 171, 2631-2636 (2003).

66. Barnes, P.J. Mediators of chronic obstructive pulmonary disease. Pharmacol. Rev. 56, 515-548 (2004).

67. Houghton, A.M. et al. Elastin fragments drive disease progression in a murine model of emphysema. J. Clin. Invest. 116, 753-759 (2006).

68. Kurosaka, K., Chen, Q., Yarovinsky, F., Oppenheim, J.J. \& Yang, D. Mouse cathelin-related antimicrobial peptide chemoattracts leukocytes using formyl peptide receptor-like 1/mouse formyl peptide receptor-like 2 as the receptor and acts as an immune adjuvant. J. Immunol. 174, 6257-6265 (2005).

69. Chertov, O. et al. Identification of human neutrophil-derived cathepsin G and azurocidin/CAP37 as chemoattractants for mononuclear cells and neutrophils. J. Exp. Med. 186, 739-747 (1997).
70. de la Rosa, G., Yang, D., Tewary, P., Varadhachary, A. \& Oppenheim, J.J. Lactoferrin acts as an alarmin to promote the recruitment and activation of APCs and antigen-specific immune responses. J. Immunol. 180, 6868-6876 (2008).

71. Wittamer, V., Bondue, B., Guillabert, A., Vassart, G., Parmentier, M. \& Communi, D. Neutrophil-mediated maturation of chemerin: a link between innate and adaptive immunity. J. Immunol. 175, 487-493 (2005).

72. Wittamer, V. et al. Specific recruitment of antigen-presenting cells by chemerin, a novel processed ligand from human inflammatory fluids. $J$. Exp. Med. 198, 977-985 (2003).

73. Hasday, J.D., Bascom, R., Costa, J.J., Fitzgerald, T. \& Dubin, W. Bacterial endotoxin is an active component of cigarette smoke. Chest 115, 829-835 (1999).

74. Doz, E. et al. Cigarette smoke-induced pulmonary inflammation is TLR4/ MyD88 and IL-1R1/MyD88 signaling dependent. J. Immunol. 180, 1169-1178 (2008).

75. Pace, E. et al. Cigarette smoke increases Toll-like receptor 4 and modifies lipopolysaccharide-mediated responses in airway epithelial cells. Immunology 124, 401-411 (2008).

76. Calderwood, S.K., Mambula, S.S. \& Gray, P.J. Extracellular heat shock proteins in cell signaling and immunity. Ann. N.Y. Acad. Sci. 1113, 28-39 (2007).

77. Pinot, F., el Yaagoubi, A., Christie, P., Dinh-Xuan, A.T. \& Polla, B.S. Induction of stress proteins by tobacco smoke in human monocytes: modulation by antioxidants. Cell Stress Chaperones 2, 156-161 (1997).

78. Li, C.J., Ning, W., Matthay, M.A., Feghali-Bostwick, C.A. \& Choi, A.M. MAPK pathway mediates EGR-1-HSP70-dependent cigarette smokeinduced chemokine production. Am. J. Physiol. Lung Cell Mol. Physiol. 292, L1297-L1303 (2007).

79. Dumitriu, I.E., Bianchi, M.E., Bacci, M., Manfredi, A.A. \& Rovere-Querini, P. The secretion of HMGB1 is required for the migration of maturing dendritic cells. J. Leukoc. Biol. 81, 84-91 (2006).

80. Yang, D., Chen, Q., Yang, H., Tracey, K.J., Bustin, M. \& Oppenheim, J.J. High mobility group box-1 (HMGB1) protein induces the migration and activation of human dendritic cells and acts as an alarmin. J. Leukoc. Biol. 81, 59-66 (2006).

81. Morbini, P., Villa, C., Campo, I., Zorzetto, M., Inghilleri, S. \& Luisetti, M. The receptor for advanced glycation end products and its ligands: a new inflammatory pathway in lung disease? Mod. Pathol. 19, 14371445 (2006).

82. Reynolds, P.R., Kasteler, S.D., Cosio, M.G., Sturrock, A., Huecksteadt, T. \& Hoidal, J.R. RAGE: developmental expression and positive feedback regulation by Egr-1 during cigarette smoke exposure in pulmonary epithelial cells. Am. J. Physiol. Lung Cell Mol. Physiol. 294, L1094-L1101 (2008).

83. Lotze, M.T. \& Tracey, K.J. High-mobility group box 1 protein (HMGB1): nuclear weapon in the immune arsenal. Nat. Rev. Immunol. 5, 331-342 (2005).

84. Andersson, U. et al. High mobility group 1 protein (HMG-1) stimulates proinflammatory cytokine synthesis in human monocytes. J. Exp. Med. 192, 565-570 (2000).

85. Termeer, C. et al. Oligosaccharides of Hyaluronan activate dendritic cells via toll-like receptor 4. J. Exp. Med. 195, 99-111 (2002).

86. Scheibner, K.A., Lutz, M.A., Boodoo, S., Fenton, M.J., Powell, J.D. \& Horton, M.R. Hyaluronan fragments act as an endogenous danger signal by engaging TLR2. J. Immunol. 177, 1272-1281 (2006).

87. McDevitt, C.A., Beck, G.J., Ciunga, M.J. \& O'Brien, J. Cigarette smoke degrades hyaluronic acid. Lung 167, 237-245 (1989).

88. Kodaira, Y., Nair, S.K., Wrenshall, L.E., Gillboa, E. \& Platt, J.L. Phenotypic and functional maturation of dendritic cells mediated by heparan sulfate. J. Immunol. 165, 1599-1604 (2000).

89. Lee, S.H. et al. Antielastin autoimmunity in tobacco smoking-induced emphysema. Nat. Med. 13, 567-569 (2007).

90. Thorley, A.J. \& Tetley, T.D. Pulmonary epithelium, cigarette smoke, and chronic obstructive pulmonary disease. Int. J. Chron. Obstruct. Pulmon. Dis. 2, 409-428 (2007).

91. Yao, H. et al. Cigarette smoke-mediated inflammatory and oxidative responses are strain-dependent in mice. Am. J. Physiol. Lung Cell Mol. Physiol. 294, L1174-L1186 (2008).

92. Rahman, I. \& Adcock, I.M. Oxidative stress and redox regulation of lung inflammation in COPD. Eur. Respir. J. 28, 219-242 (2006). 
93. Yoshida, T. \& Tuder, R.M. Pathobiology of cigarette smoke-induced chronic obstructive pulmonary disease. Physiol. Rev. 87, 1047-1082 (2007).

94. Rahman, I. Oxidative stress, chromatin remodeling and gene transcription in inflammation and chronic lung diseases. J. Biochem. Mol. Biol. 36, 95-109 (2003).

95. Nakahara, T., Moroi, Y., Uchi, H. \& Furue, M. Differential role of MAPK signaling in human dendritic cell maturation and Th1/Th2 engagement. J. Dermatol. Sci. 42, 1-11 (2006).

96. Vassallo, R., Kroening, P.R., Parambil, J. \& Kita, H. Nicotine and oxidative cigarette smoke constituents induce immune-modulatory and proinflammatory dendritic cell responses. Mol. Immunol. 45, 3321-3329 (2008).

97. Matos, T.J., Duarte, C.B., Gonçalo, M. \& Lopes, M.C. Role of oxidative stress in ERK and p38 MAPK activation induced by the chemical sensitizer DNFB in a fetal skin dendritic cell line. Immunol. Cell Biol. 83, 607-614 (2005).

98. Kirkham, P.A., Spooner, G., Ffoulkes-Jones, C. \& Calvez, R. Cigarette smoke triggers macrophage adhesion and activation: role of lipid peroxidation products and scavenger receptor. Free Radic. Biol. Med. 35, 697-710 (2003).

99. Arredouani, M.S. et al. Scavenger receptors SR-AI/II and MARCO limit pulmonary dendritic cell migration and allergic airway inflammation. J. Immunol. 178, 5912-5920 (2007).

100. Vassallo, R., Tamada, K., Lau, J.S., Kroening, P.R. \& Chen, L. Cigarette smoke extract suppresses human dendritic cell function leading to preferential induction of th-2 priming. J. Immunol. 175, 2684-2691 (2005).

101. Kroening, P.R., Barnes, T.W., Pease, L., Limper, A., Kita, H. \& Vassallo, R. Cigarette smoke-induced oxidative stress suppresses generation of dendritic cell IL-12 and IL-23 through ERK-dependent pathways. J. Immunol. 181, 1536-1547 (2008).

102. Eisenbarth, S.C., Piggott, D.A., Huleatt, J.W., Visintin, I., Herrick, C.A. \& Bottomly, K. Lipopolysaccharide-enhanced, toll-like receptor 4dependent $\mathrm{T}$ helper cell type 2 responses to inhaled antigen. J. Exp. Med. 196, 1645-1651 (2002).

103. Dabbagh, K., Dahl, M.E., Stepick-Biek, P. \& Lewis, D.B. Toll-like receptor 4 is required for optimal development of Th2 immune responses: role of dendritic cells. J. Immunol. 168, 4524-4530 (2002).

104. Bevelander, M. et al. Nitrogen dioxide promotes allergic sensitization to inhaled antigen. J. Immunol. 179, 3680-3688 (2007).

105. Redecke, V. et al. Cutting edge: activation of Toll-like receptor 2 induces a Th2 immune response and promotes experimental asthma. J. Immunol. 172, 2739-2743 (2004).

106. Piggott, D.A. et al. MyD88-dependent induction of allergic Th2 responses to intranasal antigen. J. Clin. Invest. 115, 459-467 (2005).

107. Exley, C., Begum, A., Woolley, M.P. \& Bloor, R.N. Aluminum in tobacco and cannabis and smoking-related disease. Am. J. Med. 119, 276.e9276.e11 (2006).

108. Kool, M. et al. Alum adjuvant boosts adaptive immunity by inducing uric acid and activating inflammatory dendritic cells. J. Exp. Med. 205, 869-882 (2008).

109. Eisenbarth, S.C., Colegio, O.R., O'Connor, W., Sutterwala, F.S. \& Flavell, R.A. Crucial role for the Nalp3 inflammasome in the immunostimulatory properties of aluminium adjuvants. Nature 453, 1122-1126 (2008).

110. Sutterwala, F.S. et al. Critical role for NALP3/CIAS1/Cryopyrin in innate and adaptive immunity through its regulation of caspase-1. Immunity $\mathbf{2 4}$, 317-327 (2006).

111. Duncan, J.A. et al. Cryopyrin/NALP3 binds ATP/dATP, is an ATPase, and requires ATP binding to mediate inflammatory signaling. Proc. Natl. Acad. Sci. USA 104, 8041-8046 (2007).

112. Idzko, M. et al. Extracellular ATP triggers and maintains asthmatic airway inflammation by activating dendritic cells. Nat. Med. 13, 913-919 (2007).

113. Caruso, M., Holgate, S.T. \& Polosa, R. Adenosine signalling in airways. Curr. Opin. Pharmacol. 6, 251-256 (2006).

114. Mohsenin, A. \& Blackburn, M.R. Adenosine signaling in asthma and chronic obstructive pulmonary disease. Curr. Opin. Pulm. Med. 12, 54-59 (2006).

115. Schmitz, J. et al. IL-33, an interleukin-1-like cytokine that signals via the IL-1 receptor-related protein ST2 and induces T helper type 2associated cytokines. Immunity 23, 479-490 (2005).

116. Allakhverdi, Z., Smith, D.E., Comeau, M.R. \& Delespesse, G. Cutting edge: the ST2 ligand IL-33 potently activates and drives maturation of human mast cells. J. Immunol. 179, 2051-2054 (2007).
117. Komai-Koma, M., Xu, D., Li, Y., McKenzie, A.N., Mclnnes, I.B. \& Liew, F.Y. IL-33 is a chemoattractant for human Th2 cells. Eur. J. Immunol. 37, 2779-2786 (2007).

118. Wang, Y.H. \& Liu, Y.J. The IL-17 cytokine family and their role in allergic inflammation. Curr. Opin. Immunol. 20, 697-702 (2008).

119. Wakashin, H. et al. IL-23 and Th17 cells enhance Th2 cell-mediated eosinophilic airway inflammation in mice. Am. J. Respir. Crit. Care Med. 178, 1023-1032 (2008).

120. Harrison, O.J., Foley, J., Bolognese, B.J., Long, E., Podolin, P.L. \& Walsh, P.T. Airway infiltration of CD4+ CCR6 + Th17 type cells associated with chronic cigarette smoke induced airspace enlargement. Immunol. Lett. 121, 13-21 (2008).

121. Melgert, B.N. et al. Effects of 4 months of smoking in mice with ovalbumin-induced airway inflammation. Clin. Exp. Allergy 37, 1798-1808 (2007).

122. Peterson, J.D., Herzenberg, L.A., Vasquez, K. \& Waltenbaugh, C. Glutathione levels in antigen-presenting cells modulate Th1 versus Th2 response patterns. Proc. Natl. Acad. Sci. USA 95, 3071-3076 (1998).

123. Riedl, M.A. \& Nel, A.E. Importance of oxidative stress in the pathogenesis and treatment of asthma. Curr. Opin. Allergy Clin. Immunol. 8, 49-56 (2008).

124. Agrawal, S. et al. Cutting edge: different Toll-like receptor agonists instruct dendritic cells to induce distinct Th responses via differential modulation of extracellular signal-regulated kinase-mitogen-activated protein kinase and c-Fos. J. Immunol. 171, 4984-4989 (2003).

125. Dillon, S. et al. A Toll-like receptor 2 ligand stimulates Th2 responses in vivo, via induction of extracellular signal-regulated kinase mitogenactivated protein kinase and c-Fos in dendritic cells. J. Immunol. 172, 4733-4743 (2004).

126. Puig-Kröger, A. et al. Extracellular signal-regulated protein kinase signaling pathway negatively regulates the phenotypic and functional maturation of monocyte-derived human dendritic cells. Blood 98 , 2175-2182 (2001).

127. Williams, M.A. et al. Disruption of the transcription factor Nrf2 promotes Pro-oxidative dendritic cells that stimulate Th2-like immunoresponsiveness upon activation by ambient particulate matter. J. Immunol. 181, 4545-4559 (2008).

128. Rangasamy, T. et al. Disruption of Nrf2 enhances susceptibility to severe airway inflammation and asthma in mice. J. Exp. Med. 202, 47-59 (2005).

129. Rangasamy, T. et al. Genetic ablation of Nrf2 enhances susceptibility to cigarette smoke-induced emphysema in mice. J. Clin. Invest. 114, 1248-1259 (2004).

130. Traidl-Hoffmann, C. et al. Pollen-associated phytoprostanes inhibit dendritic cell interleukin-12 production and augment Thelper type 2 cell polarization. J. Exp. Med. 201, 627-636 (2005).

131. Olivera, D.S., Boggs, S.E., Beenhouwer, C., Aden, J. \& Knall, C. Cellular mechanisms of mainstream cigarette smoke-induced lung epithelial tight junction permeability changes in vitro. Inhal. Toxicol. 19, 13-22 (2007).

132. Gangl, K. et al. Cigarette smoke facilitates allergen penetration across respiratory epithelium. Allergy. E-pub ahead of print, doi:10.1111/ j.1398-9995.2008.01861.x (2008).

133. Stampfli, M. et al. GM-CSF transgene expression in the airway allows aerosolized ovalbumin to induce allergic sensitization in mice. J. Clin. Invest. 102, 1704-1714 (1998).

134. Wang, J. et al. Transgenic expression of granulocyte-macrophage colony-stimulating factor induces the differentiation and activation of a novel dendritic cell population in the lung. Blood 95, 2337-2345 (2000).

135. Liu, Y.J. et al. TSLP: an epithelial cell cytokine that regulates T cell differentiation by conditioning dendritic cell maturation. Annu. Rev. Immunol. 25, 193-219 (2007).

136. Nakamura, Y. et al. Cigarette smoke extract induces thymic stromal lymphopoietin expression, leading to $\mathrm{T}(\mathrm{H}) 2$-type immune responses and airway inflammation. J. Allergy Clin. Immunol. 122, 1208-1214 (2008).

137. Zhang, K., Shan, L., Rahman, M.S., Unruh, H., Halayko, A.J. \& Gounni, A.S. Constitutive and inducible thymic stromal lymphopoietin expression in human airway smooth muscle cells: role in COPD. Am. J. Physiol. Lung Cell Mol. Physiol. 293, L375-L382 (2007).

138. Lee, C.G. et al. Vascular endothelial growth factor (VEGF) induces remodeling and enhances $\mathrm{TH} 2$-mediated sensitization and inflammation in the lung. Nat. Med. 10, 1095-1103 (2004). 
139. Koyama, S. et al. Vascular endothelial growth factor mRNA and protein expression in airway epithelial cell lines in vitro. Eur. Respir. J. 20, 1449-1456 (2002).

140. Miyahara, N. et al. Leukotriene b4 receptor 1 expression on dendritic cells is required for the development of th2 responses and allergeninduced airway hyperresponsiveness. J. Immunol. 181, 1170-1178 (2008).

141. Terawaki, K. et al. Absence of leukotriene B4 receptor 1 confers resistance to airway hyperresponsiveness and Th2-type immune responses. J. Immunol. 175, 4217-4225 (2005).

142. Okunishi, K., Dohi, M., Nakagome, K., Tanaka, R. \& Yamamoto, K. A novel role of cysteinyl leukotrienes to promote dendritic cell activation in the antigen-induced immune responses in the lung. J. Immunol. 173, 6393-6402 (2004).

143. Fauler, J. \& Frölich, J.C. Cigarette smoking stimulates cysteinyl leukotriene production in man. Eur. J. Clin. Invest. 27, 43-47 (1997).

144. Gualde, N. \& Harizi, H. Prostanoids and their receptors that modulate dendritic cell-mediated immunity. Immunol. Cell Biol. 82, 353-360 (2004).

145. Kali ski, P., Hilkens, C.M., Snijders, A., Snijdewint, F.G. \& Kapsenberg, M.L. Dendritic cells, obtained from peripheral blood precursors in the presence of PGE2, promote Th2 responses. Adv. Exp. Med. Biol. 417, 363-367 (1997).

146. Kubo, S. et al. E-prostanoid (EP)2/EP4 receptor-dependent maturation of human monocyte-derived dendritic cells and induction of helper T2 polarization. J. Pharmacol. Exp. Ther. 309, 1213-1220 (2004).

147. Ekberg-Jansson, A. et al. Bronchial mucosal mast cells in asymptomatic smokers relation to structure, lung function and emphysema. Respir. Med. 99, 75-83 (2005).

148. Thomas, P.S., Schreck, R.E. \& Lazarus, S.C. Tobacco smoke releases performed mediators from canine mast cells and modulates prostaglandin production. Am. J. Physiol. 263, L67-L72 (1992).

149. Mortaz, E. et al. Cigarette smoke stimulates the production of chemokines in mast cells. J. Leukoc. Biol. 83, 575-580 (2008).

150. Caron, G. et al. Histamine polarizes human dendritic cells into Th2 cellpromoting effector dendritic cells. J. Immunol. 167, 3682-3686 (2001).

151. Theiner, G., Gessner, A. \& Lutz, M.B. The mast cell mediator PGD(2) suppresses IL-12 release by dendritic cells leading to Th2 polarized immune responses in vivo. Immunobiology 211, 463-472 (2006).
152. Idzko, M. et al. Sphingosine 1-phosphate induces chemotaxis of immature and modulates cytokine-release in mature human dendritic cells for emergence of Th2 immune responses. FASEB J. 16, 625-627 (2002).

153. Mazzoni, A., Siraganian, R.P., Leifer, C.A. \& Segal, D.M. Dendritic cell modulation by mast cells controls the $\mathrm{TH} 1 / \mathrm{TH} 2$ balance in responding T cells. J. Immunol. 177, 3577-3581 (2006).

154. Liu, Y.J. et al. TSLP: an epithelial cell cytokine that regulates T cell differentiation by conditioning dendritic cell maturation. Annu. Rev. Immunol. 25, 193-219 (2006).

155. Miller, R.L. \& Ho, S.M. Environmental epigenetics and asthma: current concepts and call for studies. Am. J. Respir. Crit. Care Med. 177, 567-573 (2008).

156. Adcock, I.M., Ford, P., Ito, K. \& Barnes, P.J. Epigenetics and airways disease. Respir. Res. 7, 21 (2006).

157. Marwick, J.A. et al. Cigarette smoke alters chromatin remodeling and induces proinflammatory genes in rat lungs. Am. J. Respir. Cell Mol. Biol. 31, 633-642 (2004).

158. Adenuga, D., Yao, H., March, T.H., Seagrave, J. \& Rahman, I. Histone. Deacetylase 2 is phosphorylated, ubiquitinated and degraded by cigarette smoke. Am. J. Respir. Cell Mol. Biol. E-pub ahead of print, doi:10.1165/rcmb.2008-02550C (2008).

159. Kirkham, P. \& Rahman, I. Oxidative stress in asthma and COPD: antioxidants as a therapeutic strategy. Pharmacol. Ther. 111, 476-494 (2006).

160. Reddy, P. et al. Histone deacetylase inhibition modulates indoleamine 2,3-dioxygenase-dependent DC functions and regulates experimental graft-versus-host disease in mice. J. Clin. Invest. 118, 2562-2573 (2008).

161. Wang, B., Morinobu, A., Horiuchi, M., Liu, J. \& Kumagai, S. Butyrate inhibits functional differentiation of human monocyte-derived dendritic cells. Cell Immunol. 253, 54-58 (2008).

162. Brogdon, J.L. et al. Histone deacetylase activities are required for innate immune cell control of Th1 but not Th2 effector cell function. Blood 109, 1123-1130 (2007).

163. Vlahos, R., Bozinovski, S., Hamilton, J.A. \& Anderson, G.P. Therapeutic potential of treating chronic obstructive pulmonary disease (COPD) by neutralising granulocyte macrophage-colony stimulating factor (GM-CSF). Pharmacol. Ther. 112, 106-115 (2006). 